\title{
MLN4924 induces Noxa upregulation in acute myelogenous leukemia and synergizes with Bcl-2 inhibitors
}

\author{
KLB Knorr ${ }^{1}$, PA Schneider ${ }^{2}$, XW Meng ${ }^{1,2}$, H Dai ${ }^{1,2}$, BD Smith $^{3}$, AD Hess ${ }^{3}$, JE Karp ${ }^{3}$ and SH Kaufmann ${ }^{\star, 1,2}$
}

MLN4924 (pevonedistat), an inhibitor of the Nedd8 activating enzyme (NAE), has exhibited promising clinical activity in acute myelogenous leukemia (AML). Here we demonstrate that MLN4924 induces apoptosis in AML cell lines and clinical samples via a mechanism distinct from those observed in other malignancies. Inactivation of E3 cullin ring ligases (CRLs) through NAE inhibition causes accumulation of the CRL substrate c-Myc, which transactivates the PMAIP1 gene encoding Noxa, leading to increased Noxa protein, Bax and Bak activation, and subsequent apoptotic changes. Importantly, c-Myc knockdown diminishes Noxa induction; and Noxa siRNA diminishes MLN4924-induced killing. Because Noxa also neutralizes Mcl-1, an anti-apoptotic Bcl2 paralog often upregulated in resistant AML, further experiments have examined the effect of combining MLN4924 with BH3 mimetics that target other anti-apoptotic proteins. In combination with ABT-199 or ABT-263 (navitoclax), MLN4924 exerts a synergistic cytotoxic effect. Collectively, these results provide new insight into MLN4924-induced engagement of the apoptotic machinery that could help guide further exploration of MLN4924 for AML.

Cell Death and Differentiation (2015) 22, 2133-2142; doi:10.1038/cdd.2015.74; published online 5 June 2015

MLN4924, a first-in-class inhibitor of Nedd8 activating enzyme $(\mathrm{NAE})^{1}$ currently undergoing extensive preclinical and early phase clinical testing (http://www.clinicaltrials.gov), ${ }^{2}$ induces killing of acute myelogenous leukemia (AML) cells in vitro and exhibits single-agent activity in AML in early clinical testing. ${ }^{3-5}$ The mechanistic basis for these findings, however, is incompletely understood.

Nedd8 is a small ubiquitin-like molecule that becomes covalently linked to a number of cellular proteins, including a subset of E3 ubiquitin ligases known as cullin ring ligases (CRLs). ${ }^{6,7}$ Once activated by this modification, CRLs normally facilitate ubiquitination of a defined group of protein substrates, targeting them for degradation by the proteasome. Because the proteins ubiquitinated by CRLs are involved in inhibiting cell cycle progression, proliferative signaling, and cell survival, enhanced turnover of these proteins in malignant cells confers a survival advantage. ${ }^{8,9}$ Conversely, treatment with MLN4924, which causes decreased degradation of CRL substrates, leads to cytotoxicity in transformed cells in vitro and in vivo while largely sparing normal cells and tissues. ${ }^{1,3,9}$

The mechanistic basis for the cytotoxicity of NAE inhibition varies among malignancies and is dependent upon which of the CRL substrates accumulate and demonstrate activity. ${ }^{1,10-12}$ In colon and lung cancer cells, for example, accumulation of the $C R L$ substrate chromatin licensing and DNA replication factor 1 (Cdt1), a DNA replication licensing factor, has the dominant role in MLN4924 cytotoxicity by causing DNA re-replication and subsequent apoptosis. ${ }^{1,11}$ Other mechanisms of MLN4924-induced killing involving nuclear factor kappa-light-chain-enhancer of activated B cells (NF-KB) and Redd1 have been described in a subset of diffuse large B-cell lymphoma and multiple myeloma cells, respectively. ${ }^{10,12}$ The dominant stabilized $C R L$ substrate and downstream steps governing the mechanism of MLN4924 cytotoxicity in AML are not as well defined, although induction of apoptosis has been observed. ${ }^{3,5}$

The 'intrinsic' or 'mitochondrial' apoptotic pathway is activated when Bax and Bak proteins oligomerize in the outer mitochondrial membrane and induce cytoplasmic translocation of cytochrome $c$, which promotes caspase 9 activation. ${ }^{13,14}$ Oligomerization of Bax and Bak is regulated by additional pro- and anti-apoptotic Bcl-2 family proteins. A variety of processes, including transcriptional regulation, post-translational modification, and degradation by the proteasome, modulate the expression of $\mathrm{Bcl}-2$ family members. ${ }^{13,14}$ Accordingly, relative levels of pro- and anti-apoptotic proteins reflect many input signals from within each cell and from the surrounding environment. Once expressed, pro-apoptotic BH3-only proteins such as Bim, Puma, and Noxa either bind and neutralize anti-apoptotic proteins or bind and activate Bax and Bak. ${ }^{13-16}$ Conversely, anti-apoptotic proteins, including $\mathrm{Bcl}-2, \mathrm{Bcl}-\mathrm{x}_{\mathrm{L}}$, and $\mathrm{Mcl}-1$, bind and sequester Bax, Bak, and the

\footnotetext{
${ }^{1}$ Department of Molecular Pharmacology and Experimental Therapeutics, Rochester, MN, USA; ${ }^{2}$ Division of Oncology Research, Mayo Clinic, Rochester, MN, USA and ${ }^{3}$ Division of Hematological Malignancies, Sidney Kimmel Cancer Center, Johns Hopkins, Baltimore, MD, USA

*Corresponding author: S Kaufmann, Division of Oncology Research, Mayo Clinic, Gonda 19-212, 200 First St, S.W., Rochester, MN 55905, USA. Tel: +1 507 284 8950; Fax: +1 507293 0107; E-mail: kaufmann.scott@ mayo.edu

Abbreviations: AML, acute myelogenous leukemia; Cdt1, chromatin licensing and DNA replication factor 1; Cl, combination index; CRL, cullin ring ligase; DMSO, dimethyl

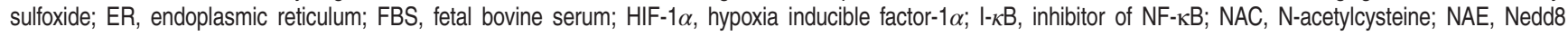
activating enzyme; NF- $\kappa$ B, nuclear factor kappa-light-chain-enhancer of activated B cells; PARP1, poly(ADP-ribose) polymerase 1; PBMC, peripheral blood mononuclear cell; PI, propidium iodide; qRTPCR, quantitative reverse transcription-polymerase chain reaction; Q-VD-OPh, N-(2-quinolyl)valyl-aspartyl-(2,6difluorophenoxy)methyl ketone; ROS, reactive oxygen species

Received 28.1.15; revised 30.4.15; accepted 04.5.15; Edited by G Melino; published online 05.6.15
} 
BH3-only proteins. ${ }^{13,14,17}$ Release of cytochrome $\mathrm{c}$ and induction of subsequent apoptotic events occur when the effects of pro-apoptotic Bcl-2 family members overcome the effects of the anti-apoptotic family members.

In studies presented here, we show that MLN4924 induces apoptosis independent of DNA re-replication via a mechanism unique to AML. Downstream of NAE inhibition, accumulation of the CRL substrate c-Myc, a transcription factor previously shown to induce apoptosis under certain conditions, ${ }^{18-20}$ has a dominant role, functioning to transcriptionally activate the PMAIP1 locus that encodes the pro-apoptotic Noxa protein in AML cell lines and clinical AML samples. Noxa subsequently binds to and neutralizes $\mathrm{Mcl}-1$, leading to activation of Bax and Bak.

Building on these results, we also demonstrate that MLN4924-induced Noxa upregulation is accompanied by increased sensitivity to $\mathrm{BH} 3$ mimetics that target antiapoptotic proteins other than Mcl-1. Two of these agents, the specific Bcl-2 inhibitor ABT-199 ${ }^{21}$ and the $\mathrm{Bcl}-2 / \mathrm{Bcl}-\mathrm{x}_{\mathrm{L}} / \mathrm{Bcl}-\mathrm{w}$ inhibitor ABT-263 (navitoclax), ${ }^{22}$ have shown activity in preclinical studies in AML. ${ }^{21,23}$ Previous studies, however, have reported that $\mathrm{Mcl}-1$, which is frequently upregulated at the time of $\mathrm{AML}$ relapse, ${ }^{24}$ confers resistance to $\mathrm{BH} 3$ mimetics. ${ }^{25-28}$ Thus, the ability of NAE inhibition to upregulate Noxa not only provides new insight into the cytotoxic action of MLN4924 in AML, but also gives impetus for further study of MLN4924/BH3 mimetic combinations.

\section{Results}

MLN4924 induces apoptosis in AML cell lines. In view of recent studies showing that MLN4924 induces apoptosis in a subset of lymphomas and in myeloma through mechanisms distinct from the Cdt1 upregulation and re-replication seen in solid tumor cells, ${ }^{10,12}$ we examined the mechanism of MLN4924-induced cytotoxicity in AML cells. In initial experiments, HL-60, U937, and ML-1 cells were treated with 30-1000 nм MLN4924 for 4-48 h, concentrations and times routinely used for MLN4924 in in vitro assays. ${ }^{1,5,10}$ At the completion of drug treatment, cells were stained with propidium iodide $(\mathrm{PI})$ and examined by flow cytometry to assess re-replication ( $>4 \mathrm{~N}$ DNA content) and apoptosis (sub-diploid, $<2 \mathrm{~N}$ DNA content). Interestingly, no DNA rereplication was observed in any of the $A M L$ cell lines between 4 and $48 \mathrm{~h}$, whereas events with sub-diploid DNA content, one of the hallmarks of apoptosis, ${ }^{29}$ appeared in a dose- and time-dependent manner (Figure 1a, Supplementary Figure S1a and b and data not shown). By $48 \mathrm{~h}$, cell lines exhibited $30-80 \%$ apoptosis at the maximum dose of $1000 \mathrm{~nm}$ (Figure 1b). Consistent with these data, apoptosis was also evident from western blots that revealed cleavage of wellestablished caspase substrates ${ }^{30}$ such as poly(ADP-ribose) polymerase 1 (PARP1) and procaspase-3 (Figure 1c), as well as flow cytometry showing increased annexin $\mathrm{V}$ staining (see below), another hallmark of apoptosis. ${ }^{31}$ Although previously noted, ${ }^{5}$ formation of reactive oxygen species (ROS) was not observed in any of the three AML lines treated with MLN4924 (Supplementary Figure S1c), whereas increased ROS were readily detected upon exposure to the positive control adaphostin, an agent that inhibits mitochondrial electron transport to induce ROS. ${ }^{32}$ Evidence of endoplasmic reticulum (ER) stress also was not present, as levels of ATF4, GRP78, and phospho-EIF2a remained unchanged in response to MLN4924 treatment (Supplementary Figure S1d). Moreover, normal peripheral blood mononuclear cells (PBMCs, Supplementary Figure S1e) and myeloid progenitors (not shown) treated with MLN4924 did not undergo appreciable apoptosis.

MLN4924-induced Noxa upregulation triggers apoptosis. In the absence of DNA re-replication, we hypothesized that apoptosis might result from alterations in $\mathrm{Bcl}-2$ family proteins. Consistent with this possibility, immunoblotting for pro- and anti-apoptotic Bcl-2 family members in cells treated with 30-1000 nM MLN4924 revealed a dosedependent increase in the pro-apoptotic protein Noxa in all three AML cell lines examined (Figure 2a). Importantly, this Noxa increase occurred in cells that were p53 null (HL-60), p53 mutant (U937) or p53 wild type (ML-1), indicating its p53 independence. Levels of other Bcl-2 family proteins did not appear to change in response to MLN4924 (Figure 2a). Cdt1, implicated in DNA re-replication to trigger apoptosis, did accumulate in response to MLN4924 treatment, although not to the same degree previously documented in solid tumors ${ }^{1,11,33}$ even though the drug was clearly active, as verified by the classic disappearance of the Nedd8-modified, active form of Cullin1 (Figure 2a, top panel). Addition of $\mathrm{N}$-acetylcysteine (NAC) during MLN4924 exposure did not alter Noxa accumulation (Supplementary Figure S2a), ruling out a contribution of ROS to the cytotoxic mechanism.

To assess whether Noxa upregulation would occur in vivo at therapeutically achievable concentrations, HL-60 xenografts were treated with three doses of MLN4924 $(90 \mathrm{mg} / \mathrm{kg}$, the maximum tolerated dose in mice) at 12-h intervals before being collected for immunoblotting. Consistent with results in vitro, inactivation of the NAE in drug-treated xenografts was evident by the absence of the Nedd8-modified Cullin1 (Figure 2b). In these studies, Noxa increased in drug-treated xenografts compared with controls, whereas Cdt1 did not (Figure 2b).

To further assess the role of Noxa in MLN4924-induced apoptosis, we utilized siRNA to downregulate Noxa. Noxa knockdown using three separate siRNAs markedly diminished MLN4924-induced apoptosis in all three AML cell lines (Figure 2c, Supplementary Figures S3a, S3b, S4a, and S4b), indicating an important role for Noxa in MLN4924 cytotoxicity.

One of the ways $\mathrm{BH} 3-$ only proteins induce apoptosis is by binding and neutralizing anti-apoptotic $\mathrm{Bcl}-2$ family members. ${ }^{14}$ In contrast to Bim or Puma, which neutralize all anti-apoptotic $\mathrm{Bcl}-2$ paralogs, Noxa preferentially binds Mcl-1. ${ }^{34,35}$ Consistent with this paradigm, Mcl-1 immunoprecipitated from MLN4924-treated cells contained increased levels of bound Noxa and decreased levels of sequestered Bak, indicating release of the latter protein from $\mathrm{Mcl}-1$ (Figure 2d). These changes were accompanied by increased levels of active Bax and Bak, as detected by staining with antibodies specific for the active conformations of these proteins (Figure 2e). 
a
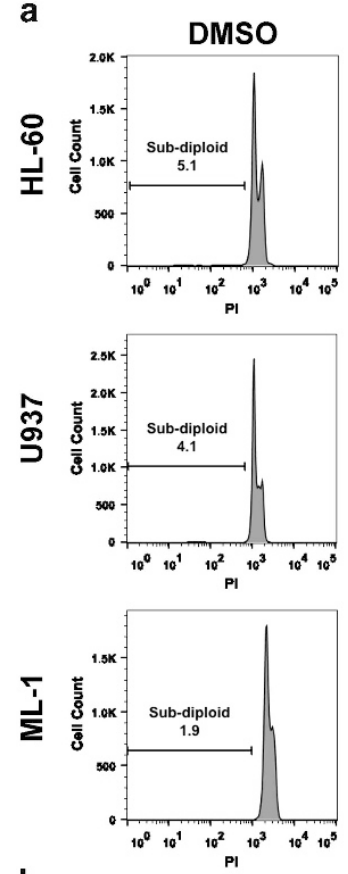

b

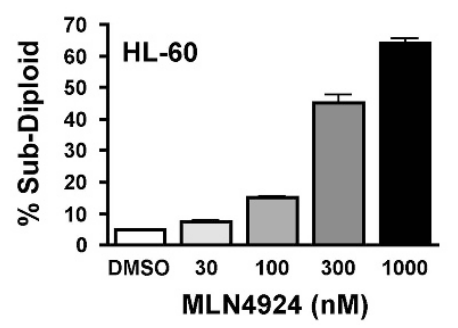

$30 \mathrm{nM}$
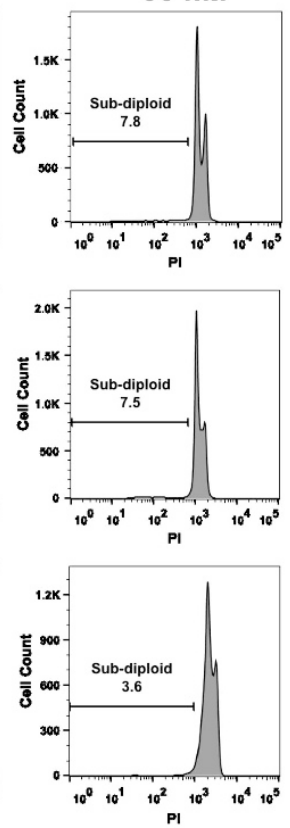
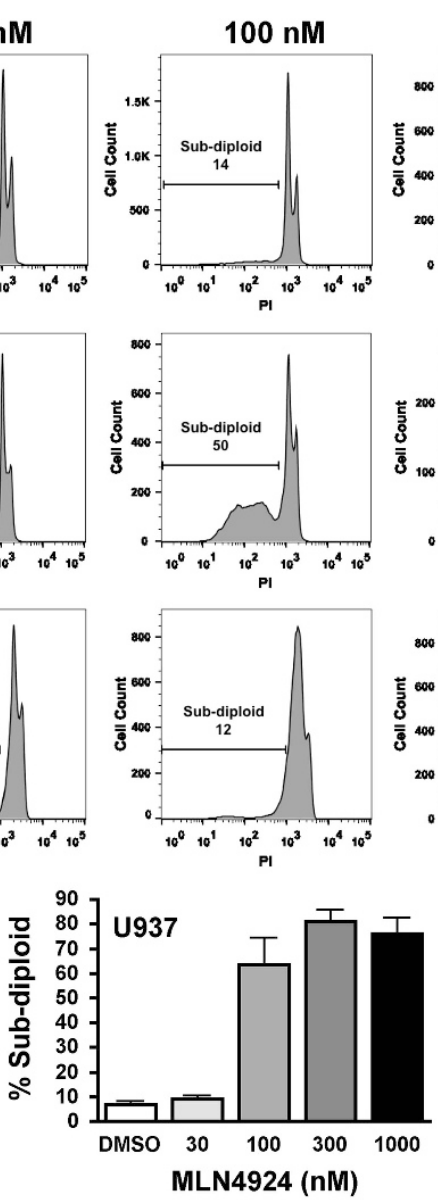
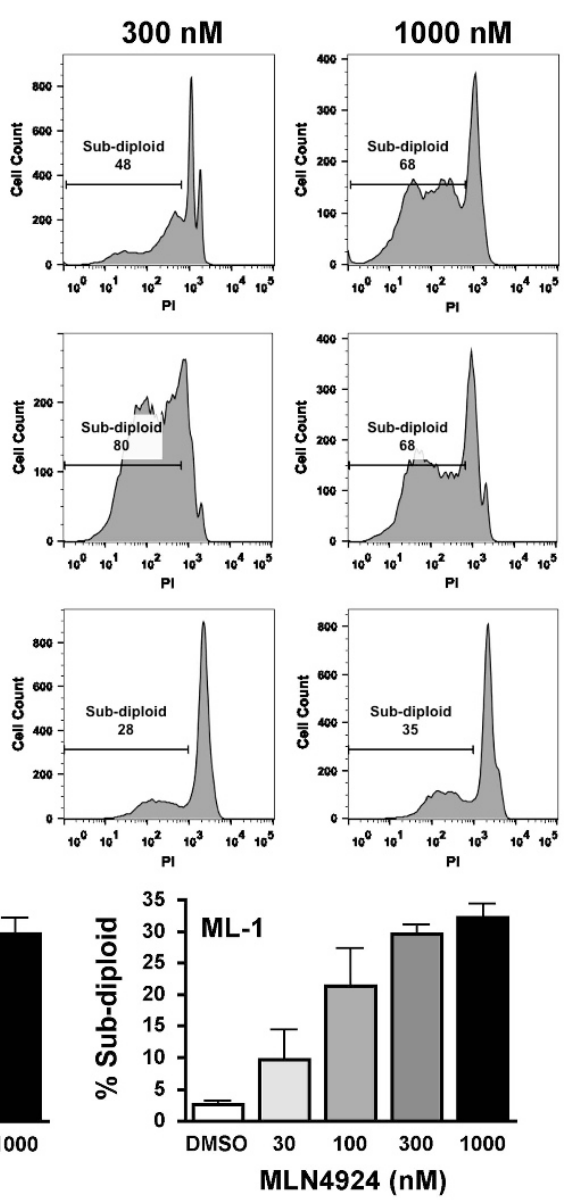

c

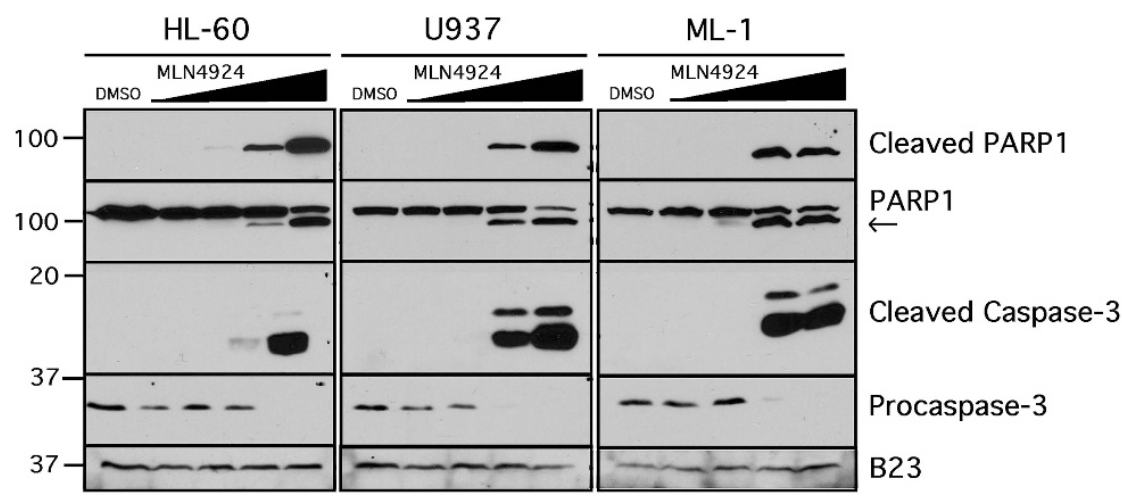

Figure 1 MLN4924 induces apoptosis in AML cell lines. (a) Flow cytometry histograms demonstrating quantification of sub-diploid populations after $48 \mathrm{~h} \mathrm{MLN4924} \mathrm{treatment}$ at 30-1000 nm in 3 AML cell lines. Data are representative of three or more independent experiments. (b) Quantification of sub-diploid population by PI staining in three AML cell lines treated with the indicated concentrations of MLN4924 for $48 \mathrm{~h}$. Error bars indicate \pm S.E.M. of three independent experiments. (c) Western blotting for caspase cleavage products indicative of apoptosis in three AML cell lines treated with increasing concentrations of MLN4924 ( $30 \mathrm{~nm}, 100 \mathrm{~nm}, 300 \mathrm{~nm}$, and $1000 \mathrm{~nm})$ for $24 \mathrm{~h}$. Arrow indicates cleaved PARP1 in PARP1 blot

Collectively, the results shown in Figures 1 and 2 demonstrate that MLN4924 induces apoptosis in AML independent of DNA re-replication and specifically as a result of increased levels of the pro-apoptotic Bcl-2 family member Noxa.

Contribution of transcriptional activation to Noxa accumulation. We next sought to determine the link between $C R L$ inhibition and Noxa protein upregulation. When protein synthesis was inhibited with cycloheximide, there was no detectable increase in Noxa half-life in MLN4924- versus diluent-treated cells, suggesting that stabilization has little if any role in MLN4924-induced Noxa upregulation (data not shown). We next utilized quantitative reverse transcriptionpolymerase chain reaction (qRTPCR) to assess Noxa transcript levels in cells treated with MLN4924 for 6-48 h. Noxa mRNA was increased at early time points and remained elevated or continued to increase further at $48 \mathrm{~h}$ (Figure 3a), 
a

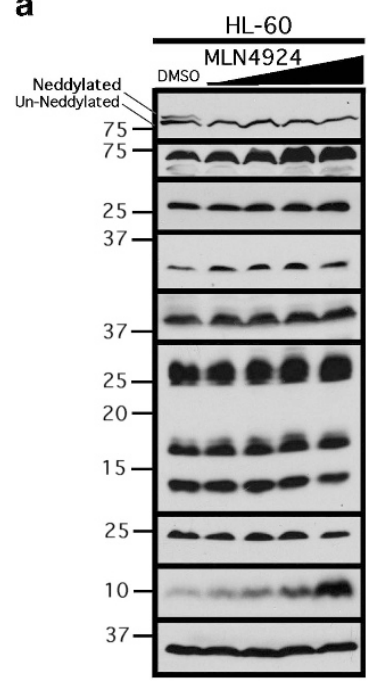

d

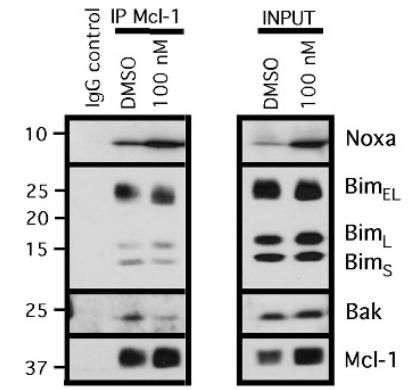

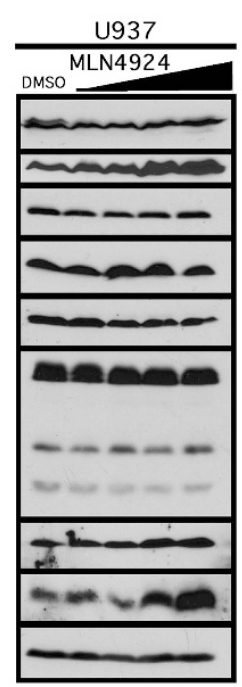

e

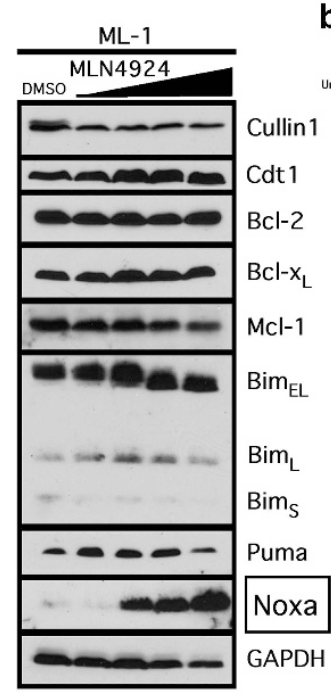

b

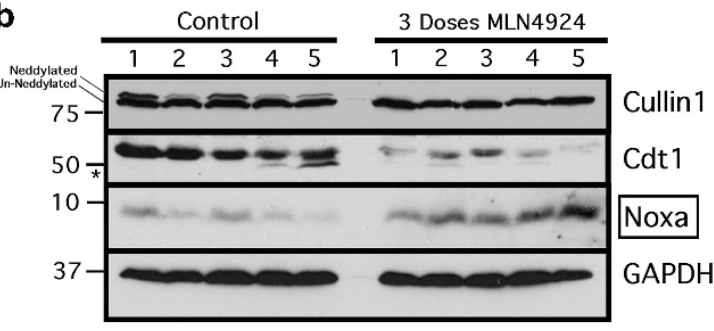

C
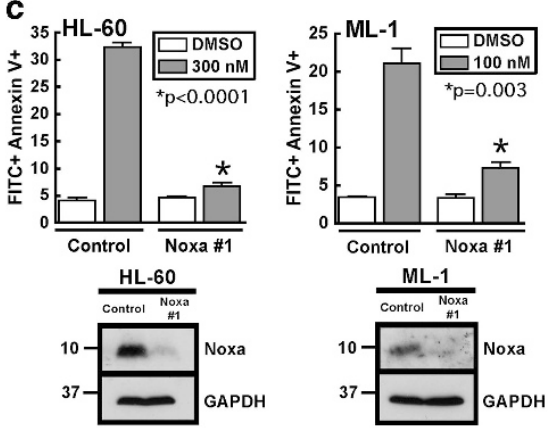
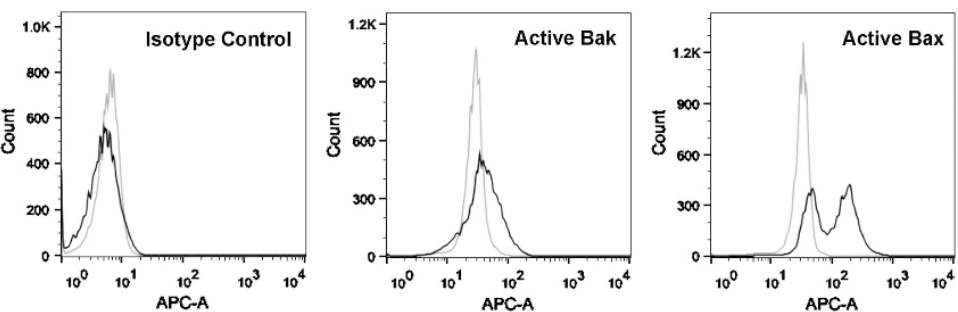

DMSO

MLN4924

Figure 2 MLN4924-induced Noxa upregulation triggers apoptosis. (a) Western blotting of three AML cell lines treated with increasing concentrations of MLN4924 (30 nM, $100 \mathrm{~nm}, 300 \mathrm{~nm}$, or $1000 \mathrm{~nm}$ ) for $48 \mathrm{~h}$. The broad spectrum caspase inhibitor Q-VD-OPh ${ }^{56}$ was included ( $\left.5 \mu \mathrm{M}\right)$ in these experiments and all subsequent experiments in which cells were collected for immunoblotting or qRTPCR to prevent caspase-mediated lysis of cells with the largest increase in pro-apoptotic Bcl-2 family members. (b) Western blotting of $\mathrm{HL}-60$ xenograft samples from five control animals and five animals treated with three doses of MLN4924 at 12-h intervals. (c) After transfection with the indicated siRNA and incubation for $6 \mathrm{~h}$, cells were treated for $24 \mathrm{~h}$ with the indicated MLN4924 concentration and assayed for Annexin V binding (upper panels) or collected for immunoblotting (lower panels). * indicates $P$-values from Student $t$-tests for Noxa siRNA versus control siRNA in MLN4924-treated cultures. Error bars indicate \pm S.E.M. of three independent experiments. (d) After ML-1 cells were treated with MLN4924 or DMSO for $24 \mathrm{~h}$, cell lysates (input) and Mcl-1 immunoprecipitates were probed with antibodies against the

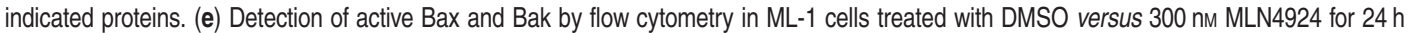

paralleling the time course for increases in Noxa protein (Figure 3b). Accordingly, MLN4924-induced Noxa upregulation appears to reflect a marked increased in Noxa mRNA.

To determine whether the increased transcript levels result from transcriptional activation of the PMAIP1 gene, which encodes Noxa, we assayed Noxa promoter activity using a luciferase reporter plasmid. A $1430 \mathrm{bp}$ sequence spanning the region -1200 bp to +230 bp relative to the Noxa transcription start site was selected based on previous reports describing functionally important sites for binding of transcription factors (including C-Myc, hypoxia inducible factor-1a (HIF-1a), and others) within this region. ${ }^{36}$ MLN4924 increased luciferase activity in cells transfected with this plasmid (Figure $3 c$ ), supporting the hypothesis that MLN4924 causes Noxa upregulation through transactivation of the Noxa promoter.

A number of transcription factors that are known to mediate Noxa gene expression, including p53, NF-kB, and c-Myc, are CRL substrates. ${ }^{9,36,37}$ As indicated above, p53 is not critical for MLN4924-induced Noxa upregulation, as this upregulation was seen in p53 null (HL-60) as well as p53 wild-type cells (ML-1; Figures 3a and C). NF-kB does not appear to have a critical role because, consistent with previous reports, ${ }^{10,38}$
NF-KB levels decreased upon MLN4924 treatment and levels of the NF-kB inhibitor (I-kB) increased (Supplementary Figure S2c). Levels of ATF4, another transcription factor implicated in Noxa upregulation, ${ }^{39}$ also did not increase (Supplementary Figure S1c), consistent with the observation that MLN4924-induced Noxa upregulation and apoptosis in these AML lines occurs without evidence of elevated ROS or ER stress (Supplementary Figures S1c, d and S2a, b).

Further experiments (Figure 3d) demonstrated that MLN4924-induced accumulation of c-Myc, a transcription factor that has been implicated in oncogenic stress-induced apoptosis under unfavorable growth conditions ${ }^{18-20}$ and also found to be responsible for increasing Noxa gene expression in response to the proteasome inhibitor bortezomib in some cell types. ${ }^{36}$ To assess whether c-Myc is involved in MLN4924induced Noxa upregulation, cells were transfected with control or c-Myc siRNA and treated with DMSO or MLN4924. c-Myc siRNA diminished induction of both Noxa mRNA (Figure $3 e$ and Supplementary Figure S3c) and protein (Figure $3 f$ and Supplementary Figure S3d). Although we cannot rule out a contribution from additional transcription factors such as HIF-1a, which has a role in Noxa upregulation in other 
a
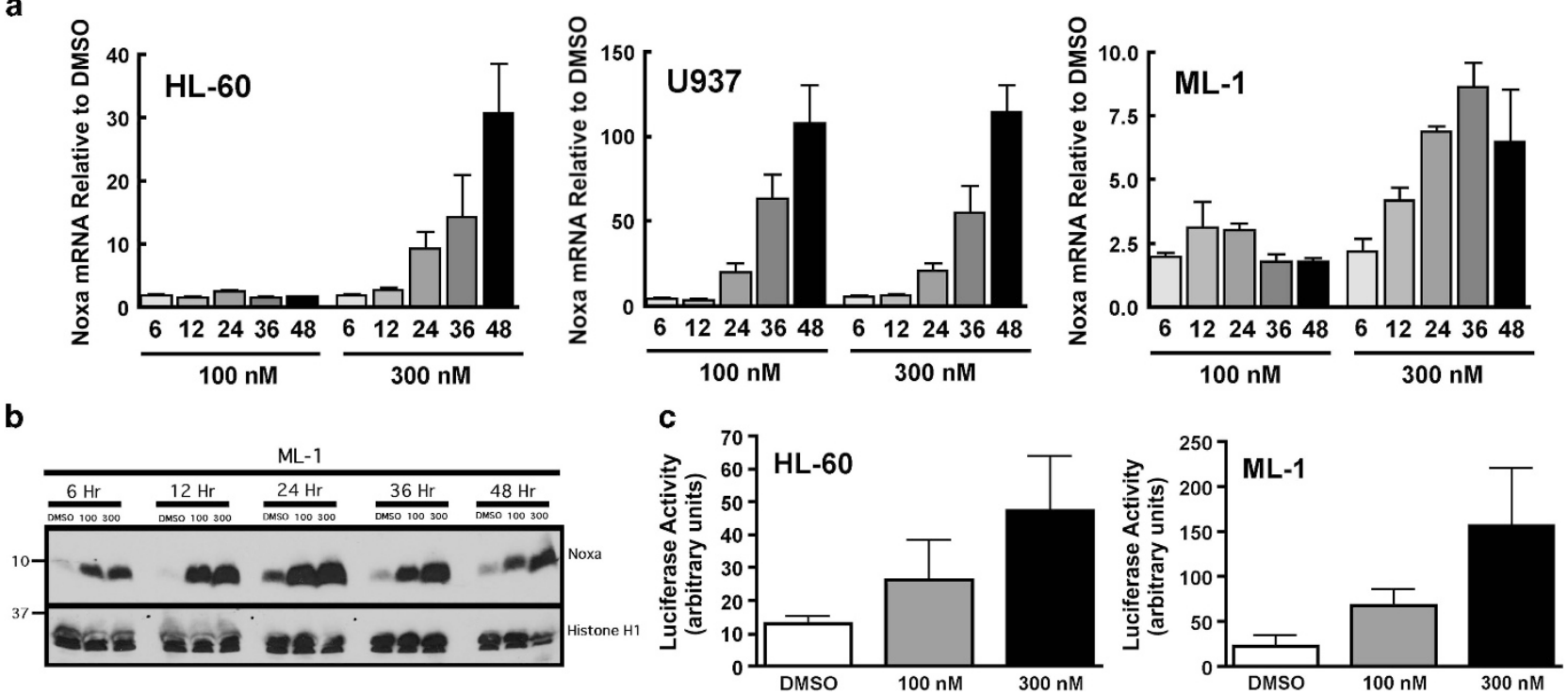

d

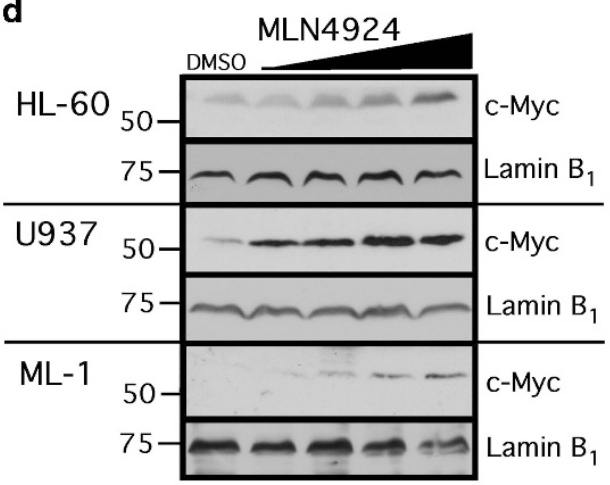

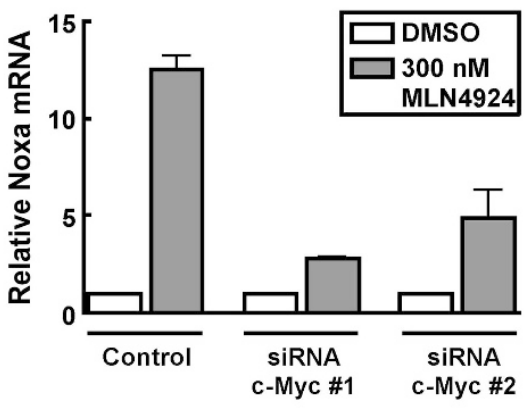

f

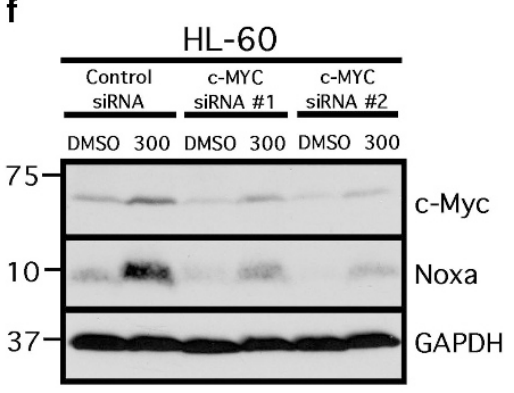

Figure 3 Noxa increases via a transcript-dependent mechanism. (a) qRTPCR quantification of Noxa mRNA in MLN4924-treated cells relative to DMSO control samples at time points from 6 to $48 \mathrm{~h}$. Error bars indicate \pm S.E.M. from three independent experiments for each cell line. (b) Representative blot of ML-1 samples collected in parallel at matched time points from a qRTPCR experiment shown in panel a. (c) Eight hours after cells were transfected with a luciferase reporter plasmid containing the Noxa promoter sequence, MLN4924 was added for 24 h. Cell lysates were then collected for luciferase activity, which was normalized to protein content. Error bars indicate \pm S.E.M. of three independent experiments for each cell line. (d) Western blotting in three AML cell lines after $24 \mathrm{~h}$ of MLN4924 treatment at increasing concentrations (30 nM, $100 \mathrm{~nm}, 300 \mathrm{~nm}$, $1000 \mathrm{~nm}$ ) versus DMSO. (e-f) Six hours after HL-60 cells were transfected with control or c-Myc siRNA, cultures were treated with DMSO or $300 \mathrm{~nm}$ MLN4924 for $18 \mathrm{~h}$ and collected for qRTPCR for Noxa mRNA (e) or subjected to immunoblotting (f). Error bars indicate \pm range of two independent experiments

systems $^{37}$ and is also upregulated in response to MLN4924 (Supplementary Figure S2d), observations in Figure 3 indicate that c-Myc upregulation has a major role in MLN4924 induction of Noxa in AML lines.

MLN4924 causes c-Myc accumulation, Noxa upregulation, and apoptosis in primary $A M L$ cells ex vivo. To assess whether MLN4924 exerts the same effects in primary AML cells, blasts from bone marrow aspirates of newly diagnosed AML were exposed to diluent or MLN4924 ex vivo for $24 \mathrm{~h}$ and then collected for PI staining, qRTPCR, and immunoblotting (Figure 4 and Supplementary Table S1). Induction of Noxa transcript and protein was observed with increasing concentrations of MLN4924 (Figures 4a and c). Likewise, accumulation of c-Myc protein was observed, in contrast to relatively limited Cdt1 accumulation. Emergence of a sub-diploid apoptotic population was also noted (Figure 4b). These events were consistently observed, albeit to varying degrees, in all six clinical AML samples analyzed.
Synergistic cytotoxic effect of MLN4924 in combination with ABT-199 and ABT-263. Several agents designed to inhibit anti-apoptotic Bcl-2 proteins are currently undergoing clinical testing in hematological malignancies. ${ }^{40}$ Most notable are ABT-199, a Bcl-2 specific inhibitor, ${ }^{41}$ and ABT-263, which inhibits $\mathrm{Bcl}-2, \mathrm{Bcl}-\mathrm{x}_{\mathrm{L}}$, and $\mathrm{Bcl}-\mathrm{w}$ but not $\mathrm{Mcl}-1 .{ }^{22} \mathrm{~A}$ similar $\mathrm{Mcl}-$ 1 inhibitor suitable for clinical trials has yet to emerge, but the ability to inhibit Mcl-1 might be important in situations where Mcl-1 contributes to drug resistance or relapse. ${ }^{24-26}$ Our observation that MLN4924 induces Noxa, which binds Mcl-1 in AML, raises the possibility that MLN4924 may serve as an alternative therapeutic approach for targeting $\mathrm{Mcl}-1$.

On the basis of these considerations, we tested MLN4924 in combination with ABT-199 and ABT-263 in AML cell lines, primary $A M L$ cell isolates, and normal PBMCs. AML cell lines were treated with $300 \mathrm{~nm}$ MLN4924 alone or in combination with increasing concentrations of ABT-199 or ABT-263 for $24 \mathrm{~h}$, collected and assayed for apoptosis by PI or Annexin V staining. Compared with single-agent treatments, increased 
apoptosis occurred in all samples that received combination treatment (Figures $5 a-f$, left panels). Analysis by the median effect method under the assumption that effects of the two agents are mutually exclusive, which is equivalent to isobologram analysis, ${ }^{42}$ indicated the effects of the ABT-199 and ABT-263 in combination with MLN4924 were synergistic (combination index $(\mathrm{Cl})<1$, Figures $5 \mathrm{a}-\mathrm{f}$, right panels).

MLN4924 and the BH3 mimetics also induced apoptosis in a synergistic fashion in primary clinical $A M L$ samples (Figures $5 \mathrm{~g}-\mathrm{i}$ ), including a case of AML that persisted a

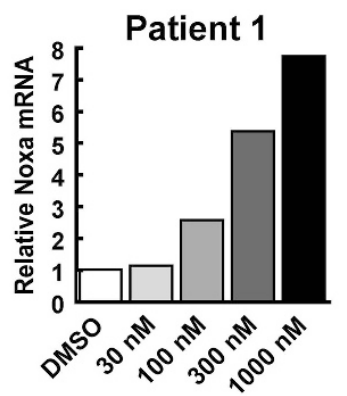

b

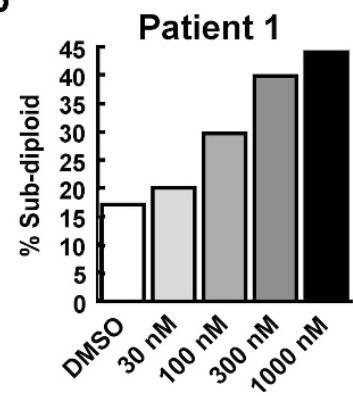

C
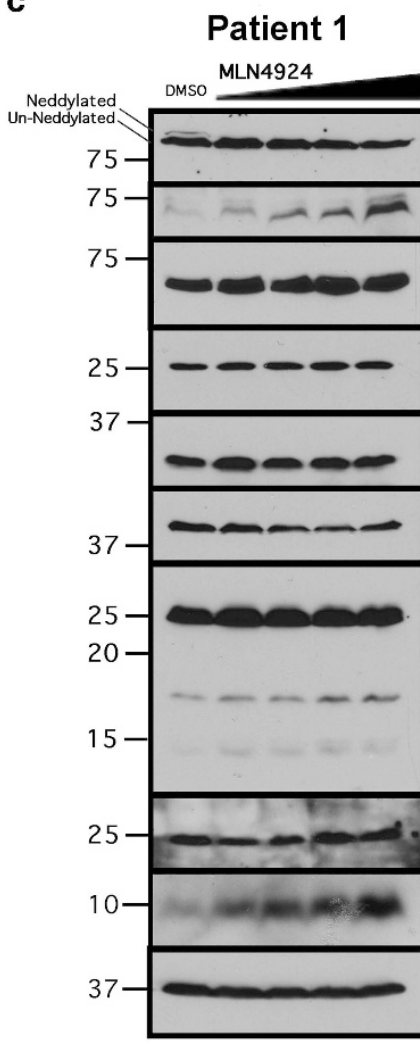

Patient 2

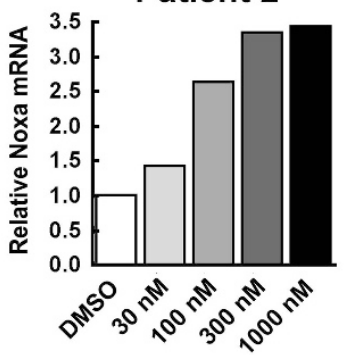

Patient 2

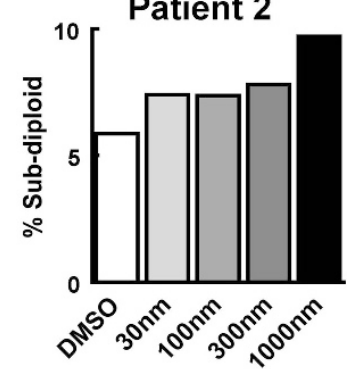

Patient 3

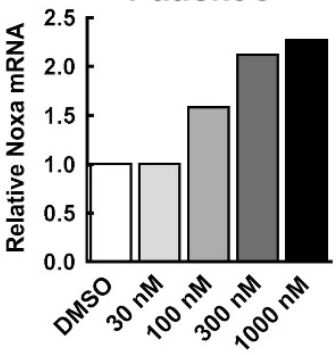

Patient 3

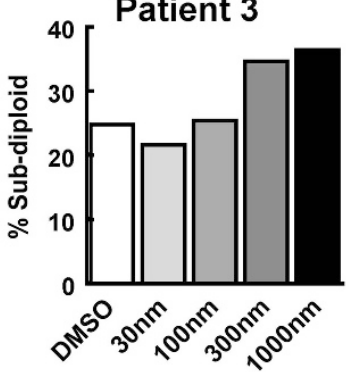

Patient 2

MLN4924

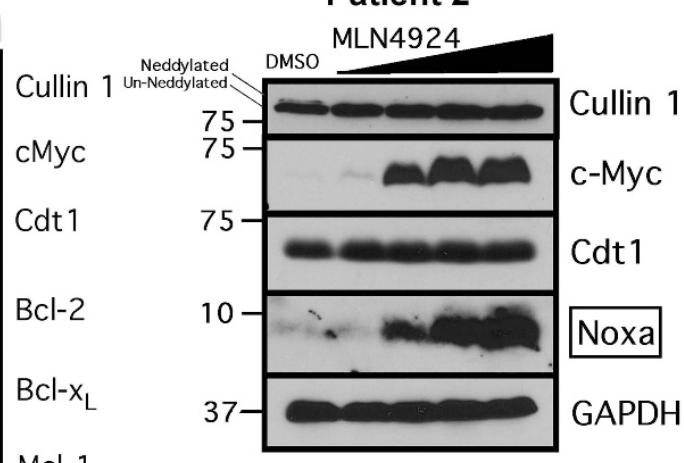

Patient 3

MLN4924 Bim $_{E L}$ Bim $_{L}$ $\mathrm{Bim}_{\mathrm{S}}$ Puma Noxa GAPDH

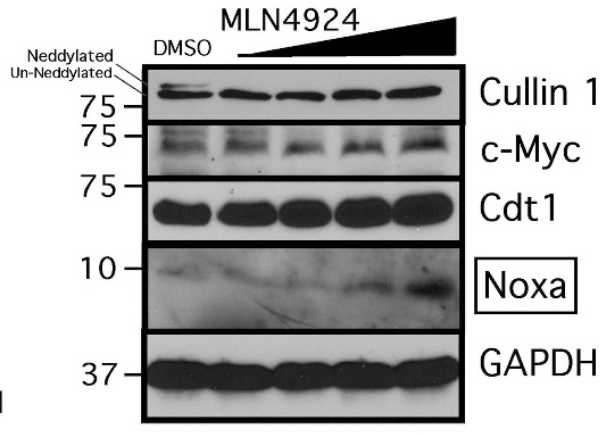

Figure 4 MLN4924 causes c-Myc accumulation, Noxa upregulation, and apoptosis in primary AML samples exposed ex vivo. Freshly isolated bone marrow leukemia cells treated with increasing concentrations of MLN4924 versus DMSO for $24 \mathrm{~h}$ were collected for qRTPCR for quantification of relative Noxa mRNA (a), PI staining and flow cytometry for quantification of sub-diploid apoptotic events (b), and western blotting to assure drug activity (un-Neddylated Cullin1) and assess levels of c-Myc and Bcl-2 family members (c). Information regarding the clinical samples is summarized in Supplementary Table S1 
a
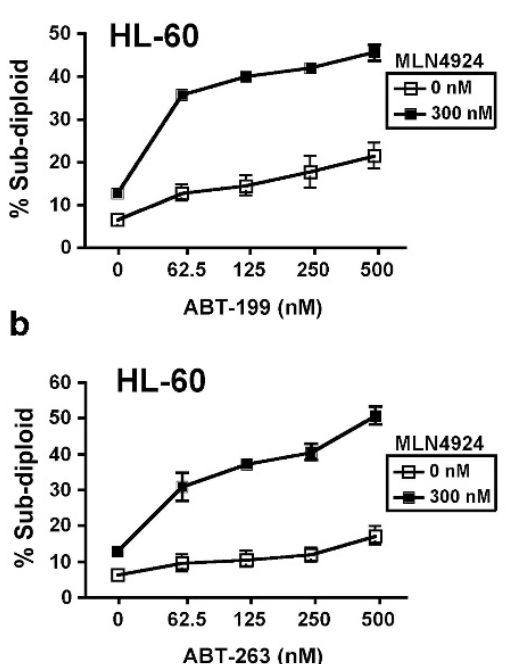

c

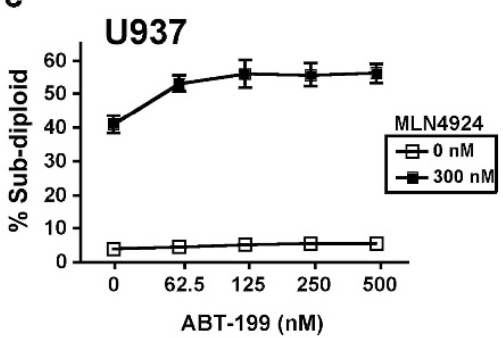

d

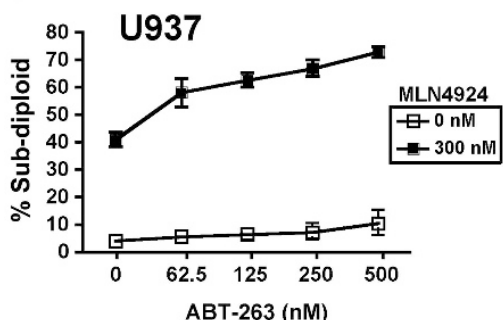

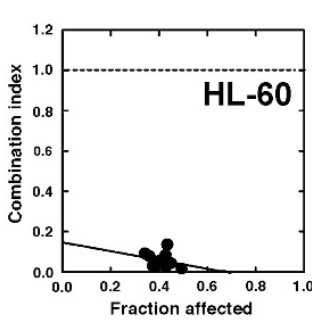

e
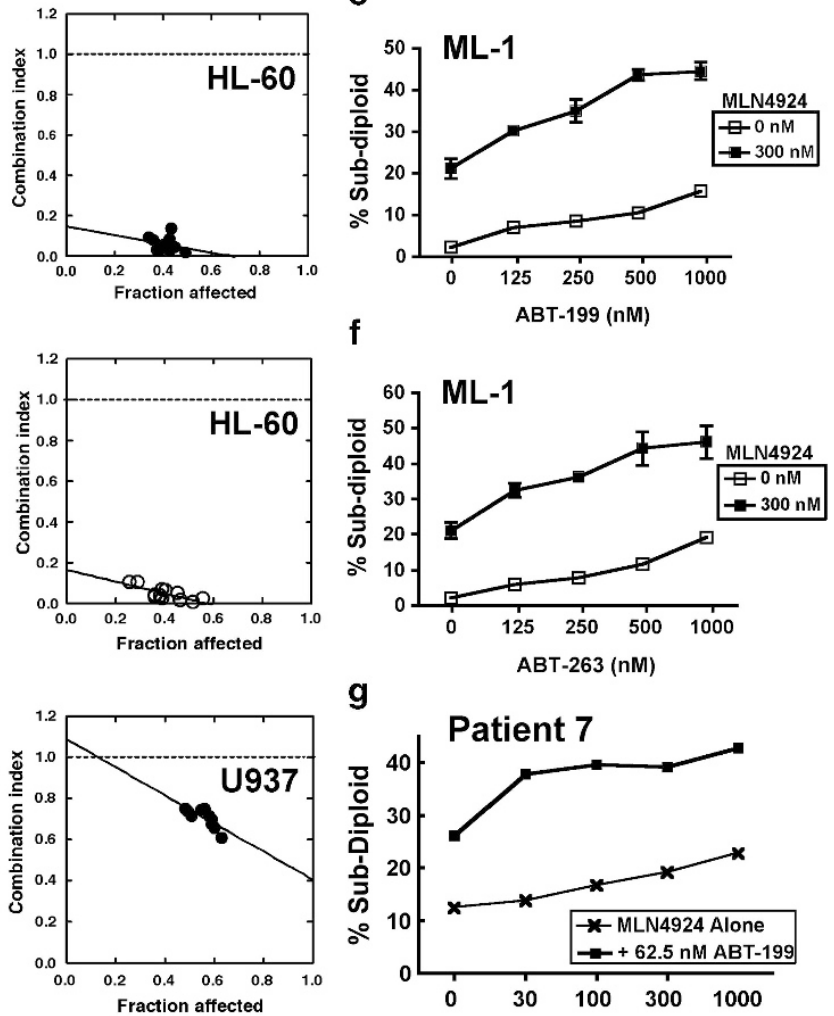

g
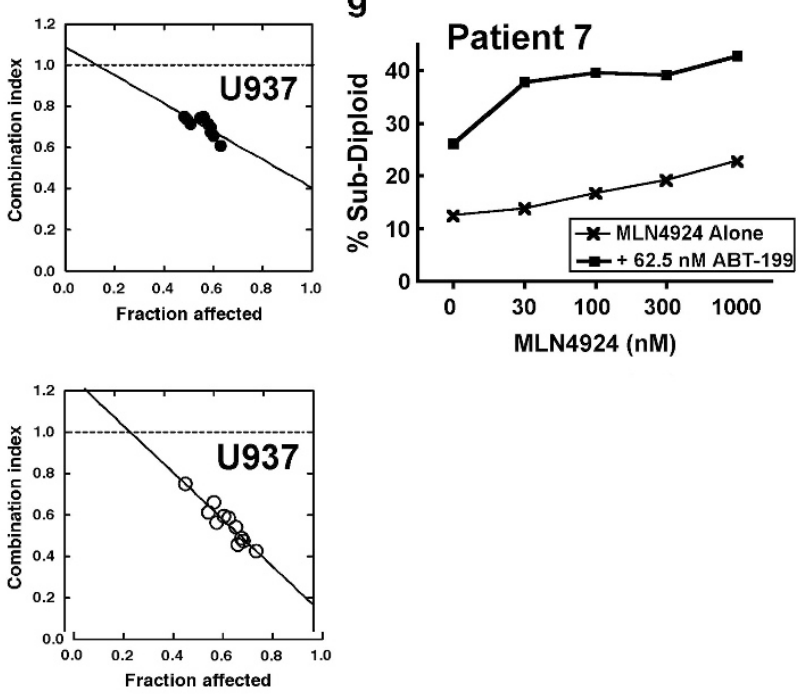
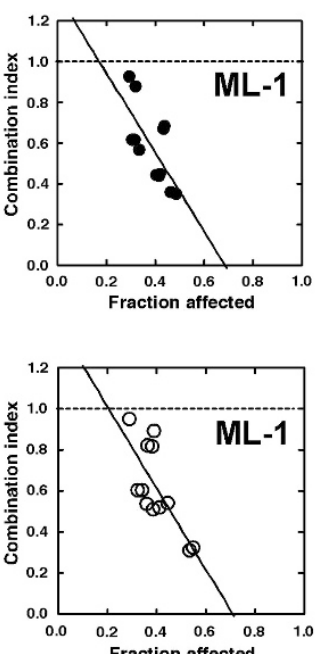

h

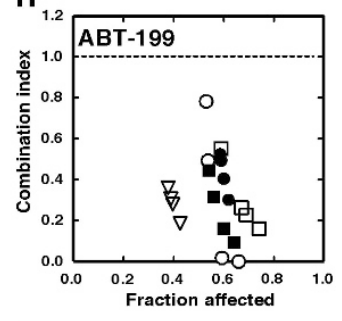

i

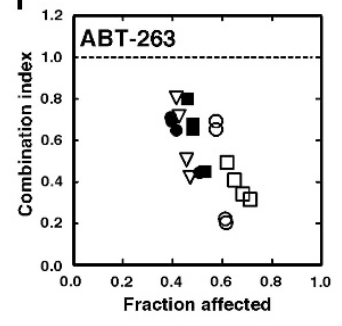

Figure 5 Synergistic cytotoxic effect of MLN4924 in combination with ABT-199 or ABT-263. (a-f; left panels) PI staining of HL-60 (a and b), U937 (c and d), and ML-1 cells (e and f) treated with MLN4924 alone or in combination with ABT-199 (a, $\mathbf{c}$ and e) or ABT-263 (b, d and f). Error bars indicate \pm S.E.M. from three independent experiments for each cell line. (right panels) Plots from panels a-f showing combination index $(\mathrm{Cl})$ as a function of fraction of cells undergoing apoptosis (fraction affected). According to this method, $\mathrm{Cl}<1.0$ indicates synergy, $\mathrm{Cl}=1$ indicates additivity, and $\mathrm{Cl}>1$ indicates antagonism. ${ }^{42}$ (g) Sub-diploid events in primary cells isolated from patient 7 (Supplementary Table S1) and treated for $24 \mathrm{~h}$ with $62.5 \mathrm{~nm} \mathrm{ABT-199}$ alone or in combination with the indicated concentrations of MLN4924. (h and i) Summary plots showing Cl as a function of the percentage of cells undergoing apoptosis in samples treated from patient 7 (open triangles), patient 8 (open circles), patient 9 (open squares), and patient 10 (closed squares) collected at diagnosis, as well as patient 8 at the time of leukemia persistence on day 14 of therapy (closed circles). Each sample was treated with a combination of $62.5 \mathrm{~nm}$ ABT-199 (h) or ABT-263 (i) with the concentrations of MLN4924 indicated in $\mathbf{g} . \mathrm{Cl}<1.0$ indicates synergy

on day 14 of therapy (Figures $5 \mathrm{~h}-\mathrm{i}$, closed circles). In contrast, when these combinations were applied to normal PBMCs, induction of apoptosis was not increased above the level induced by either ABT-199 or ABT-263 alone (Supplementary Figure S5a and b).

\section{Discussion}

Despite four decades of improvement in therapy for AML, the prognosis remains poor for certain subsets of patients, including those with antecedent hematological disorders, chemotherapy-related leukemia, and the elderly, who generally have a 5 -year survival rate of $<20 \%$. These observations highlight the need for new therapeutic agents. Preliminary reports from a Phase I clinical trial of MLN4924 in AML have indicated benefit in patients with difficult to treat relapsed and refractory disease. ${ }^{4}$ As clinical development of MLN4924 in myeloid malignancies continues (www.clinicaltrials.gov), these promising results provide the impetus for determining the mechanism of MLN4924-induced cytotoxicity downstream of NAE inhibition, understanding possible mechanisms of MLN4924 resistance in AML, and assessing possible strategies for combining MLN4924 with other agents that have activity in hematological malignancies.

Previous studies have shown that MLN4924 selectively inhibits NAE to diminish CRL function, thereby affecting 
turnover of a very select group of proteins that impact pathways critical for cell survival. ${ }^{1,9,43}$ Additional studies have shown that MLN4924 has relatively limited impact on normal cells $^{1,3}$ and exerts a cytotoxic effect in a variety of malignant cells through cell type-specific mechanisms.,10,12 For example, in solid tumor cells MLN4924-induced cytotoxicity is triggered by accumulation of CRL substrate and DNA replication licensing factor Cdt1, leading to DNA re-replication and apoptosis, ${ }^{1,11}$ whereas in multiple myeloma accumulation of Redd1 suppresses AKT and mTOR prosurvival and proliferative signaling to induce cell death. ${ }^{12}$ Although preclinical studies have indicated that MLN4924 also is cytotoxic in AML, a definitive mechanism of action has not been previously established. . $^{3,5}$

The studies presented here demonstrate that MLN4924 induces apoptosis in AML independent of DNA re-replication (Figure 1 and Supplementary Figure S1) and without evidence of increased ROS or ER stress (Supplementary Figures S1-S2), two common triggers of apoptosis. Interestingly, we observed increases in Noxa protein in cell lines (Figure 2a) and clinical isolates (Figure 4c) in vitro, as well as in $\mathrm{AML}$ xenografts at achievable MLN4924 concentrations in vivo (Figure 2b). Moreover, Noxa knockdown afforded significant protection from MLN4924-induced apoptosis (Figure 2c, Supplementary Figure S3a,b and S4a,b), demonstrating the critical role of Noxa in the cytotoxicity of MLN4924. Furthermore, Noxa upregulation was accompanied by neutralization of Mcl-1 (Figure 2d) as well as activation of Bax and Bak (Figure 2e).

The MLN4924-induced increase in Noxa protein paralleled an increase in Noxa mRNA, which occurred in both AML cell lines (Figure $3 a$ ) and clinical AML specimens (Figure 4a). In turn, the increase in Noxa mRNA accompanied increased Noxa promoter activity (Figure $3 c$ ). Although multiple transcription factors are known to transactivate the Noxa promoter, ${ }^{36,37} \mathrm{c}$-Myc was a prime candidate because it is a CRL substrate ${ }^{9}$ and has been shown to upregulate Noxa in response to the proteasome inhibitor bortezomib. ${ }^{36}$ Consistent with this hypothesis, ${ }^{20}$ we not only observed MLN4924induced accumulation of c-Myc in AML cell lines (Figure 3d) and clinical samples (Figure 4c), but also diminished accumulation of Noxa message and protein when c-Myc was knocked down (Figures $3 e$ and $f$ and Supplementary Figure S3c and d). These results complement and extend prior work showing that $\mathrm{c}-\mathrm{Myc}$, which is generally considered a contributor to proliferation, can contribute to apoptosis, ${ }^{44,45}$ particularly under unfavorable growth conditions such as those resulting from environmental alterations or pharmacological manipulation. ${ }^{18-20,36}$

Collectively, these studies are consistent with the pathway shown in Figure 6, which is different from the cytotoxic mechanism reported in solid tumor cells, ${ }^{1,33}$ chronic lymphocytic leukemia, ${ }^{38}$ lymphoma, ${ }^{10}$ or myeloma, ${ }^{12}$ and support the notion that the mechanism of MLN4924-induced cell death downstream of NAE inhibition will vary from cell type to cell type. ${ }^{1}$ Importantly, the increases in c-Myc protein, Noxa mRNA and Noxa protein observed in AML cell lines were also observed in AML samples exposed to MLN4924 ex vivo, pointing to a pharmacodynamic marker of NAE inhibition (Noxa upregulation) and possible mechanisms of MLN4924

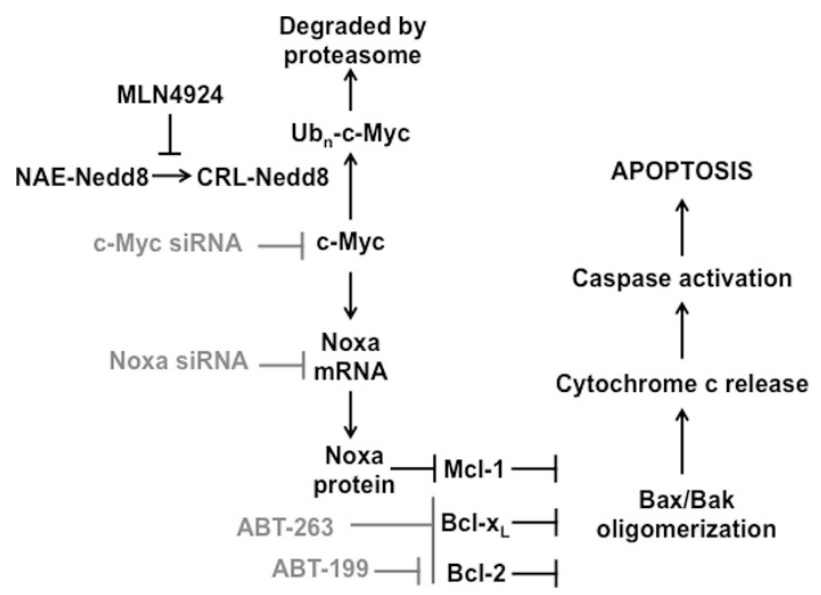

Figure 6 Summary of MLN4924 cytotoxic mechanism in AML. MLN4924 inhibits NAE to prevent CRL neddylation, thereby preventing ubiquitination of C-Myc (and other proteins). Elevated c-Myc causes transactivation of the Noxa promoter leading to increased Noxa mRNA and protein. Noxa neutralizes Mcl-1 leading to (i) Bax and Bak activation, cytochrome $c$ release, caspase activation, and apoptosis and (ii) increased sensitivity to ABT-199 and ABT-263 (navitoclax). Manipulations reported in the Results section (summarized in gray) are consistent with this model

resistance (diminished c-Myc or Noxa upregulation) that could be investigated in future trials of MLN4924 in AML.

Previous studies have demonstrated that $\mathrm{Mcl}-1$ has a critical role in a variety of hematological malignancies and solid tumors. In particular, Mcl-1 has been shown to be essential for the development and sustained growth of $\mathrm{AML}$ in murine models. ${ }^{46}$ Moreover, Mcl-1 upregulation has been noted at the time of leukemic relapse after chemotherapy in vivo. ${ }^{24}$ $\mathrm{Mcl}-1$ overexpression has also been shown to contribute to development of multiple myeloma ${ }^{47}$; and $\mathrm{Mcl}-1$ has been implicated in drug resistance in chronic lymphocytic leukemia. ${ }^{48,49}$ In addition, the gene encoding $\mathrm{Mcl}-1$ is amplified in a variety of solid tumors. ${ }^{50}$ In the case of ovarian cancer, tumors with Mcl-1 amplification have been found to be particularly resistant to conventional platinum-based chemotherapy. ${ }^{51}$

The BH3-only protein Noxa is a potent and relatively selective neutralizer of Mcl-1. ${ }^{34,52}$ Although the present study demonstrates that MLN4924 induces Noxa upregulation and Mcl-1 neutralization in AML, further studies are required to determine whether a similar mechanism will be observed in other hematological malignancies or solid tumors.

During these studies, it was reported that AML blasts are exquisitely sensitive to the Bcl-2 antagonists ABT-199 and ABT-737 ex vivo. ${ }^{21,23}$ Additional studies have shown that $\mathrm{Mcl}-1$ overexpression, which frequently occurs in $\mathrm{AML}$ at relapse ${ }^{24}$ is a mechanism of resistance to ABT-737. ${ }^{25-27}$ The ability of MLN4924 to upregulate Noxa and neutralize $\mathrm{Mcl}-1$ (Figure $2 d$ ) raised the possibility that MLN4924 might sensitize AML cells to agents such as ABT-199 and ABT-263 (an orally bioavailable analog of ABT-737), which was indeed observed (Figure 5). As MLN4924 and BH3 mimetics move forward, further preclinical and possible clinical testing of these combinations might be warranted.

In summary, the NAE inhibitor MLN4924, which has shown promising activity in relapsed and refractory $A M L$, has a unique mechanism of action in AML. Determining the best applications 
for this agent, as well as its potential in combination therapies, will require further testing in preclinical studies and clinical trials with thoughtful correlative laboratory studies.

\section{Materials and Methods}

Cells and cell culture. HL-60 (kind gift of RT Abraham), U937 (American Type Culture Collection, Manassas, VA, USA), and ML-1 (kind gift of MB Kastan) were cultured in RPMI 1640 medium (RPMl; Thermo Fisher, Waltham, MA, USA) supplemented with $10 \%$ fetal bovine serum (FBS, Sigma-Aldrich, St Louis, MO, USA). All cell lines were authenticated by short tandem-repeat profiling in the Mayo Clinic Advanced Genomics Technology Center (Rochester, MN, USA). Primary AML samples were obtained with informed consent from patients after Institutional Review Board approval. AML cells from bone marrow aspirates and mononuclear cells from normal donor peripheral blood were isolated using a standard Ficoll gradient procedure ${ }^{24}$ and resuspended in RPMI+10\% FBS for all subsequent experiments.

Chemicals and reagents. Reagents were obtained from the following suppliers: MLN4924 (Active Biochem, Maplewood, NJ, USA); ABT-199 and ABT-263 (ChemieTek, Indianapolis, IN, USA); adaphostin (Drug Synthesis and Chemistry Branch, National Cancer Institute, Bethesda, MD, USA); enhanced chemiluminescence reagents (Thermo Fisher Scientific, Waltham, MA, USA); RNeasy RNA isolation kit (Qiagen, Valencia, CA, USA); qRTPCR probes, TaqMan qRTPCR kit and 5-chloromethyl-2,7-dichlorodihydrofluorescein diacetate (Life Technologies, Grand Island, NY, USA); luciferase assay reagents (Promega, Madison, WI, USA); dimethyl sulfoxide (DMSO), PI, NAC, Triton X-100 (Sigma-Aldrich); the broad spectrum caspase inhibitor $\mathrm{N}$-(2-quinolyl)valyl-aspartyl-(2,6-difluorophenoxy) methyl ketone (Q-VD-OPh, SM Biochemicals, Anaheim, CA, USA); Matrigel and allophycocyanin-conjugated Annexin V (BD Bioscience, Franklin Lakes, NJ, USA); and Trappsol (CTD, High Springs, FL, USA). Primary antibodies were purchased as follows: Cullin1, Cdt1, Bcl-x L Mcl-1, Bim, glyceraldehyde 3-phosphate dehydro-

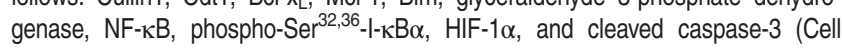
Signaling Technology, Beverly, MA, USA); Bcl-2 (Dako, Carpenteria, CA, USA); active Bak, active Bax, lamin B1 and procaspase-3 (BD Bioscience); Puma (cat no. sc-374223), and c-Myc 9E10 monoclonal (Santa Cruz Biotechnology, Dallas, TX, USA); cleaved PARP1 (Promega); and Noxa (Enzo Life Sciences, New York, NY, USA). C-2-10 anti-PARP1 was a kind gift from G Poirier (Laval University, Quebec, QC, Canada). Antibody to the nucleolar protein B23/nucleophosmin was generated as described. ${ }^{53}$

PI staining and detection of apoptosis. Cells were exposed to increasing concentrations of MLN4924 diluted in DMSO (final concentration $0.1 \%$ $\mathrm{v} / \mathrm{v}$ ) for 4-48 $\mathrm{h}$, then pelleted and stained with $\mathrm{PI}$ as previously described. ${ }^{29,31}$ After $30 \mathrm{~min}$, samples were subjected to flow cytometry using a FACSCanto II (BD Bioscience) to assess PI fluorescence intensity. Analysis and quantification of the sub- $G_{0} / G_{1}$ population was completed using FlowJo Software (TreeStar, Ashland, OR, USA). Annexin V staining was performed as previously described. ${ }^{31}$

Western blotting and qRTPCR. Cells exposed to increasing concentrations of MLN4924 or $0.1 \%$ (v/v) DMSO for $24 \mathrm{~h}$ were pelleted for protein isolation. Sample preparation, SDS-PAGE, transfer to nitrocellulose membrane and subsequent protein detection by immunoblotting were performed as previously described. ${ }^{54}$ Parallel samples were collected for RNA isolation and transcript quantification using TaqMan qRTPCR reagents as described. ${ }^{55}$ These experiments were conducted in the presence of Q-VD-OPh, a broad spectrum caspase inhibitor, ${ }^{56}$ to limit cleavage or release of proteins and transcripts of interest (owing to apoptosis and secondary to loss of membrane integrity) without affecting apoptotic events upstream of caspase activation. In western blotting studies conducted in the absence of Q-VD-OPh, B23 was used as a loading control because it generally is not cleaved by caspases. ${ }^{57}$

RNA interference. The following siRNA constructs were purchased from Ambion (Austin, TX, USA): Noxa \#1 (custom designed sequence, 5'-GGAGAUUUGGAGACAAACU-3'), Noxa \#2 (s10108, 5'-AGAUAUGAAUGUUUCUAAA-3'), Noxa \#3 (s10710, 5'-GAAACUUAGUAGAACAAAU-3'), c-Myc \#1 (s9130, 5'-GAGCUAAAACGGAGCUUCUU-3'), c-Myc \#2 (s9131, 5'-ACAGCCCACUGGUCCUCAA-3'), and Negative Control No.1 (cat. no. 4390884). Oligonucleotides were resuspended according to the supplier's instructions. All constructs were introduced into cells suspended in RPMI+10\% FBS using a BTX830 square wave electroporator (Harvard Apparatus, Holliston, MA, USA) delivering a single $10 \mathrm{~ms}$ pulse at $300 \mathrm{~V}$. To mark successfully transfected cells, samples were co-transfected with siGLO fluorescent oligonucleotide (Life Technologies). Knockdown of siRNA targets was confirmed by immunoblotting.

Beginning $6 \mathrm{~h}$ after transfection, cells were treated with MLN4924 or $0.1 \%(\mathrm{v} / \mathrm{v})$ DMSO and stained with Annexin $\mathrm{V}$ before flow cytometry or collected for protein and RNA.

Luciferase reporter assay. A portion of the PMAIP promoter (-1200 bp to +230 bp relative to the transcription start site, NCBI Gene ID 5366)-termed as the 'Noxa promoter' in this paper-was cloned into the PGL2 basic luciferase reporter plasmid using Mlu1 and Xho1 restriction sites. After the reporter plasmid suspended in intracellular buffer ${ }^{58}$ was introduced via a single $10 \mathrm{~ms}$ electroporation pulse at $300 \mathrm{~V}(\mathrm{ML}-1)$ or $327 \mathrm{~V}$ (HL-60), cells were allowed to recover for $8 \mathrm{~h}$, treated with MLN4924 or $0.1 \%(\mathrm{v} / \mathrm{v})$ DMSO for $24 \mathrm{~h}$, and collected for luciferase assays according to the manufacturer's protocol (Promega). The luciferase signal in each sample was normalized to protein concentration (measured by the bicinchoninic acid method ${ }^{59}$.

Mouse xenograft study. With approval from the Mayo Institutional Animal Care and Use Committee, female nu/nu mice received subcutaneous injections of $2 \times 10^{6} \mathrm{HL}-60$ cells in $200 \mu$ l Matrigel into the left flank. When xenografts reached $\sim 150 \mathrm{~mm}^{3}$, mice were randomized to no treatment versus 3 doses of MLN4924 $90 \mathrm{mg} / \mathrm{kg}$ subcutaneously ${ }^{5}$ in $10 \%$ Trappsol at $12-\mathrm{h}$ intervals. $12 \mathrm{~h}$ after the final dose, xenografts were collected, snap-frozen, and processed for protein isolation as previously described. ${ }^{55}$

MLN4924 combination studies. AML cell lines, primary AML cell isolates, and normal PBMCs were exposed to MLN4924 alone or in combination with ABT-199 or ABT-263 for $24 \mathrm{~h}$. Cells were then collected for PI or Annexin V staining and flow cytometry as described above. Using CalcuSyn software (Biosoft, Cambridge, UK), data were analyzed by the median effect method under the assumption that effects of the two agents are mutually exclusive, which is equivalent to isobologram analysis. ${ }^{42}$ According to this method, a $\mathrm{Cl}<1$ indicates synergy, $\mathrm{Cl}=1$ indicates additivity, and $\mathrm{Cl}>1$ indicates antagonism. ${ }^{42}$

\section{Conflict of Interest}

The authors declare no conflict of interest.

Acknowledgements. This work was supported in part by $\mathrm{NIH}$ grants $\mathrm{F} 30$ CA183507 (KLBK), T32 GM65841 (KLBK), R01 CA166704 (SHK), and P30 CA06973 and U01 CA70095 (to support sample acquisition). SHK is a member of the Mayo Clinic Cancer Center (P30 CA15083). We thank Karen Flatten and Kevin Peterson for technical support and Deb Strauss for administrative assistance.

1. Soucy TA, Smith PG, Milhollen MA, Berger AJ, Gavin JM, Adhikari S et al. An inhibitor of NEDD8-activating enzyme as a new approach to treat cancer. Nature 2009; 458: 732-736.

2. Nawrocki ST, Griffin P, Kelly KR, Carew JS. MLN4924: a novel first-in-class inhibitor of NEDD8-activating enzyme for cancer therapy. Expert Opin Investig Drugs 2012; 21: 1563-1573.

3. Sen S, De Leon JP, Smith PG, Roboz GJ, Guzman ML. Investigational NEDD8-activating enzyme (NAE) inhibitor, MLN4924, demonstrates activity against primary AML blast, progenitor and stem cell populations. ASH Annu Meet Abstr 2011; 118: 1414.

4. Swords RT, Erba HP, DeAngelo DJ, Smith PG, Pickard MD, Dezube BJ et al. The novel, investigational NEDD8-activating enzyme inhibitor MLN4924 in adult patients with acute myeloid leukemia (AML) or high-grade myelodysplastic syndromes (MDS): a phase 1 study. ASH Annu Meet Abstr 2010; 116: 658

5. Swords RT, Kelly KR, Smith PG, Garnsey JJ, Mahalingam D, Medina E et al. Inhibition of NEDD8-activating enzyme: a novel approach for the treatment of acute myeloid leukemia. Blood 2010; 115: 3796-3800.

6. Rabut G, Peter M. Function and regulation of protein neddylation. 'Protein modifications: beyond the usual suspects' review series. EMBO Rep 2008; 9: 969-976.

7. Watson IR, Irwin MS, Ohh M. NEDD8 pathways in cancer, Sine Quibus Non. Cancer Cell 2011; 19: 168-176.

8. Duncan K, Schafer G, Vava A, Parker MI, Zerbini LF. Targeting neddylation in cancer therapy. Future Oncol 2012; 8: 1461-1470.

9. Soucy TA, Smith PG, Rolfe M. Targeting NEDD8-activated cullin-RING ligases for the treatment of cancer. Clin Cancer Res 2009; 15: 3912-3916. 
10. Milhollen MA, Traore T, Adams-Duffy J, Thomas MP, Berger AJ, Dang $L$ et al. MLN4924, a NEDD8-activating enzyme inhibitor, is active in diffuse large B-cell lymphoma models: rationale for treatment of NF-kB-dependent lymphoma. Blood 2010; 116: 1515-1523.

11. Lin JJ, Milhollen MA, Smith PG, Narayanan U, Dutta A. NEDD8-targeting drug MLN4924 elicits DNA rereplication by stabilizing Cdt1 in S phase, triggering checkpoint activation, apoptosis, and senescence in cancer cells. Cancer Res 2010; 70: 10310-10320.

12. Gu Y, Kaufman JL, Bernal L, Torre C, Matulis SM, Harvey RD et al. MLN4924, an investigational NAE inhibitor, suppresses AKT and mTOR signaling pathway through up regulating REDD1 in human myeloma cells. Blood 2014; 123: 3269-3276.

13. Taylor RC, Cullen SP, Martin SJ. Apoptosis: controlled demolition at the cellular level. Nat Rev Mol Cell Biol 2008; 9: 231-241.

14. Strasser A, Cory S, Adams JM. Deciphering the rules of programmed cell death to improve therapy of cancer and other diseases. EMBO J 2011; 30: 3667-3683.

15. Walensky LD, Gavathiotis E. BAX unleashed: the biochemical transformation of an inactive cytosolic monomer into a toxic mitochondrial pore. Trends Biochem Sci 2011; 36 642-652.

16. Dai H, Smith A, Meng XW, Schneider PA, Pang YP, Kaufmann SH. Transient binding of an activator $\mathrm{BH} 3$ domain to the Bak $\mathrm{BH} 3$-binding groove initiates Bak oligomerization. J Cell Biol 2011; 194: 39-48.

17. Llambi F, Moldoveanu T, Tait SW, Bouchier-Hayes L, Temirov J, McCormick LL et al. A Unified model of mammalian BCL-2 protein family interactions at the mitochondria. Mol Cell 2011; 44: 517-531.

18. Evan GI, Wyllie AH, Gilbert CS, Littlewood TD, Land H, Brooks M et al. Induction of apoptosis in fibroblasts by c-myc protein. Cell 1992; 69: 119-128.

19. Egle A, Harris AW, Bouillet $P$, Cory $S$. Bim is a suppressor of Myc-induced mouse $B$ cell leukemia. Proc Natl Acad Sci USA 2004; 101: 6164-6169.

20. Hoffman B, Liebermann DA. Apoptotic signaling by c-MYC. Oncogene 2008; 27: 6462-6472.

21. Pan R, Hogdal LJ, Benito JM, Bucci D, Han L, Borthakur G et al. Selective BCL-2 inhibition by ABT-199 causes on-target cell death in acute myeloid leukemia. Cancer Discov 2014; 4 362-375.

22. Tse C, Shoemaker AR, Adickes J, Anderson MG, Chen J, Jin S et al. ABT-263: a potent and orally bioavailable Bcl-2 family inhibitor. Cancer Res 2008; 68: 3421-3428.

23. Vo TT, Ryan J, Carrasco R, Neuberg D, Rossi DJ, Stone RM et al. Relative mitochondrial priming of myeloblasts and normal HSCs determines chemotherapeutic success in AML. Cell 2012; 151: 344-355.

24. Kaufmann SH, Karp JE, Svingen PA, Krajewski S, Burke PJ, Gore SD. Elevated expression of the apoptotic regulator Mcl-1 at the time of leukemic relapse. Blood 1998; 91: 991-1000.

25. van Delft MF, Wei AH, Mason KD, Vandenberg CJ, Chen L, Czabotar PE et al. The $\mathrm{BH} 3$ mimetic $\mathrm{ABT}-737$ targets selective $\mathrm{Bcl}-2$ proteins and efficiently induces apoptosis via Bak/Bax if Mcl-1 is neutralized. Cancer Cell 2006; 10: 389-399.

26. Konopleva M, Contractor R, Tsao T, Samudio I, Ruvolo PP, Kitada S et al. Mechanisms of apoptosis sensitivity and resistance to the $\mathrm{BH} 3$ mimetic $\mathrm{ABT}-737$ in acute myeloid leukemia. Cancer Cell 2006; 10: 375-388.

27. Chen S, Dai Y, Harada H, Dent P, Grant S. Mcl-1 down-regulation potentiates ABT-737 lethality by cooperatively inducing Bak activation and Bax translocation. Cancer Res 2007; 67: 782-791.

28. Yecies D, Carlson NE, Deng J, Letai A. Acquired resistance to ABT-737 in lymphoma cells that up-regulate MCL-1 and BFL-1. Blood 2010; 115: 3304-3313

29. Nicoletti I, Migliorati G, Pagliacci MC, Grignani F, Riccardi C. A rapid and simple method for measuring thymocyte apoptosis by propidium iodide staining and flow cytometry. $\mathrm{J}$ Immunol Meth 1991; 139: 271-279.

30. Earnshaw WC, Martins LM, Kaufmann SH. Mammalian caspases: structure, activation, substrates and functions during apoptosis. Annu Rev Biochem 1999; 68: 383-424.

31. Lee SH, Meng XW, Flatten KS, Loegering DA, Kaufmann SH. Phosphatidylserine exposure during apoptosis reflects bidirectional trafficking between plasma membrane and cytoplasm. Cell Death Differ 2013; 20: 64-76.

32. Le SB, Hailer MK, Buhrow S, Wang Q, Pediaditakis P, Bible KC et al. Inhibition of mitochondrial respiration as a source of adaphostin-induced reactive oxygen species and cytotoxicity. J Biol Chem 2007; 282: 8860-8872.

33. Blank JL, Liu XJ, Cosmopoulos K, Bouck DC, Garcia K, Bernard H et al. Novel DNA damage checkpoints mediating cell death induced by the NEDD8-activating enzyme inhibitor MLN4924. Cancer Res 2013; 73: 225-234.

34. Chen L, Willis SN, Wei A, Smith BJ, Fletcher JI, Hinds MG et al. Differential targeting of prosurvival $\mathrm{Bcl}-2$ proteins by their $\mathrm{BH} 3-$ only ligands allows complementary apoptotic function. Mol Cell 2005; 17: 393-403.
35. Correia C, Schneider PA, Dai H, Dogan A, Maurer MJ, Church AK et al. BCL2 mutations are associated with increased risk of transformation and shortened survival in follicular lymphoma. Blood 2015; 125: 658-667.

36. Nikiforov MA, Riblett M, Tang WH, Gratchouck V, Zhuang D, Fernandez Y et al. Tumor cellselective regulation of NOXA by c-MYC in response to proteasome inhibition. Proc Natl Acad Sci USA 2007; 104: 19488-19493.

37. Kim JY, Ahn HJ, Ryu JH, Suk K, Park JH. BH3-only protein Noxa is a mediator of hypoxic cell death induced by hypoxia-inducible factor 1alpha. J Exp Med 2004; 199: 113-124.

38. Godbersen JC, Humphries LA, Danilova OV, Kebbekus PE, Brown JR, Eastman A et al. The Nedd8-activating enzyme inhibitor MLN4924 thwarts microenvironment-driven NF-kappaB activation and induces apoptosis in chronic lymphocytic leukemia B cells. Clin Cancer Res 2014; 20: 1576-1589.

39. Albershardt TC, Salerni BL, Soderquist RS, Bates DJ, Pletnev AA, Kisselev AF et al. Multiple $\mathrm{BH} 3$ mimetics antagonize antiapoptotic MCL1 protein by inducing the endoplasmic reticulum stress response and up-regulating BH3-only protein NOXA. J Biol Chem 2011; 286: 24882-24895.

40. Billard C. BH3 mimetics: status of the field and new developments. Mol Cancer Ther 2013; 12: $1691-1700$

41. Souers AJ, Leverson JD, Boghaert ER, Ackler SL, Catron ND, Chen J et al. ABT-199, a potent and selective BCL-2 inhibitor, achieves antitumor activity while sparing platelets. Nature Med 2013; 19: 202-208.

42. Berenbaum MC. What is synergy? Pharmacol Rev 1989; 41: 93-141.

43. Brownell JE, Sintchak MD, Gavin JM, Liao H, Bruzzese FJ, Bump NJ et al. Substrateassisted inhibition of ubiquitin-like protein-activating enzymes: the NEDD8 E1 inhibitor MLN4924 forms a NEDD8-AMP mimetic in situ. Mol Cell 2010; 37: 102-111.

44. Vaux DL, Cory S, Adams JM. Bcl-2 gene promotes haemopoietic cell survival and cooperates with c-myc to immortalize pre-B cells. Nature 1988; 335: 440-442.

45. Strasser A, O'Connor L, Huang DC, O'Reilly LA, Stanley ML, Bath ML et al. Lessons from bcl-2 transgenic mice for immunology, cancer biology and cell death research. Behring Inst Mitt 1996: 101-117.

46. Glaser SP, Lee EF, Trounson E, Bouillet P, Wei A, Fairlie WD et al. Anti-apoptotic Mcl-1 is essential for the development and sustained growth of acute myeloid leukemia. Genes Dev 2012; 26: 120-125.

47. Zhang B, Gojo I, Fenton RG. Myeloid cell factor-1 is a critical survival factor for multiple myeloma. Blood 2002; 99: 1885-1893.

48. Kitada S, Andersen J, Akar S, Zapata JM, Takayama S, Krajewski S et al. Expression of apoptosis-regulating proteins in chronic lymphocytic leukemia: correlations with in vitro and in vivo chemoresponses. Blood 1998; 91: 3379-3389.

49. Yeh YY, Chen R, Hessler J, Mahoney E, Lehman AM, Heerema NA et al. Up-regulation of CDK9 kinase activity and Mcl-1 stability contributes to the acquired resistance to cyclindependent kinase inhibitors in leukemia. Oncotarget 2015; 6: 2667-2679.

50. Beroukhim R, Mermel CH, Porter D, Wei G, Raychaudhuri S, Donovan J et al. The landscape of somatic copy-number alteration across human cancers. Nature 2010; 463: 899-905.

51. Topp MD, Hartley L, Cook M, Heong V, Boehm E, McShane L et al. Molecular correlates of platinum response in human high-grade serous ovarian cancer patient-derived xenografts. Mol Oncol 2014; 8: 656-668.

52. Smith AJ, Dai H, Correia C, Takahashi R, Lee SH, Schmitz I et al. Noxa/Bcl-2 protein interactions contribute to bortezomib resistance in human lymphoid cells. J Biol Chem 2011; 286: 17682-17692.

53. Fields AP, Kaufmann SH, Shaper JH. Analysis of the internal nuclear matrix. oligomers of a 38 kD nucleolar polypeptide stabilized by disulfide bonds. Exp Cell Res 1986; 164: 139-153.

54. Kaufmann SH, Svingen PA, Gore SD, Armstrong DK, Cheng Y-C, Rowinsky EK. Altered formation of topotecan-stabilized topoisomerase I-DNA adducts in human leukemia cells. Blood 1997; 89: 2098-2104.

55. Gupta M, Wahner Hendrickson A, Seongseouk Y, Han JJ, Schneider PA, Stenson M et al. Dual TORC1/TORC2 inhibition diminishes Akt activation and induces puma-dependent apoptosis in lymphoid malignancies. Blood 2012; 119: 476-487.

56. Caserta TM, Smith AN, Gultice AD, Reedy MA, Brown TL. Q-VD-OPh, a broad spectrum caspase inhibitor with potent antiapoptotic properties. Apoptosis 2003; 8: 345-352.

57. Kaufmann SH. Induction of endonucleolytic DNA cleavage in human acute myelogenous leukemia cells by etoposide, camptothecin, and other cytotoxic anticancer drugs: a cautionary note. Cancer Res 1989; 49: 5870-5878.

58. van den Hoff MJ, Moorman AF, Lamers WH. Electroporation in 'intracellular' buffer increases cell survival. Nucleic Acids Res 1992; 20: 2902.

59. Smith PK, Krohn RI, Hermanson GT, Mallia AK, Gartner FH, Provenzano MD et al. Measurement of protein using bicinchoninic acid. Anal Biochem 1985; 150: 76-85.

\section{Supplementary Information accompanies this paper on Cell Death and Differentiation website (http://www.nature.com/cdd)}

